\title{
Case study of life cycle assessment on battery container
}

\author{
Laurence $^{1^{*}}$ and Josephine Kasena ${ }^{1}$ \\ ${ }^{1}$ Industrial Engineering Department, Universitas Pelita Harapan, Tangerang, Indonesia
}

\begin{abstract}
Every year, the total of plastic industry in Indonesia grows rapidly. Not only giving positive effects on economic, but industrial development also causing a negative impact on the environment. Those negative impacts are caused by inefficiently using of resources and industrial waste which could pollute the environment. Therefore, it is necessary to calculate the impact itself by using the Life Cycle Assessment (LCA) method. The LCA could help us to take better decision to improve the production process and products which could minimize the energy consumption and resources. PT XYZ is a plastic injection company. This company hasn't collected, calculated and analysed their products and production process which may contribute to environmental damage. Therefore, this study will collect the data about the potential environmental impact which caused by the product of PT XYZ. LCA was performed at plastic car battery container type "X" and type "Y" using IMPACT 2002+ method in SimaPro8 software. The result of data calculation showing that the potential environmental impact is more dominant in these categories: respiratory inorganics, non-renewable energy, and global warming. The component which caused the greatest potential for respiratory inorganics and global warming is coming from electrical energy consumption (lignite).
\end{abstract}

\section{Introduction}

In modern days, the total of plastic industry in Indonesia grows rapidly. Industrial development had a positive impact on the economy but had a negative impact on the environment. These negative impacts are caused by the inefficient use of natural resources and the presence of industrial waste that can pollute the environment [1]. These environmental impacts can be measured using the Life Cycle Assessment (LCA) approach. From the 17 sustainable development goals, responsible production and consumption is the one that close relationship with the production floor. It is expected that in the end, the company have a good implementation in implementing life cycle perspective in day to day operation in every managerial level. Life Cycle Assessment (LCA) is an approach to measuring the environmental impact caused by the product or activity start from collecting raw materials, followed by the production process, product usage and disposal/waste management. The importance of LCA is that it can help as a better decision-making tool to

\footnotetext{
*Corresponding author: laurence.fti@uph.edu
} 
improve the production process and product systems such as minimizing energy and resource consumption [2]. Company XYZ is a plastic injection factory that produces a variety of automotive parts and electronic parts. But unfortunately this factory has become one of the factories that have never carried out data collection, calculation, and analysis of the potential environmental impacts of the production activities carried out.

\subsection{Problem statement}

The absence of information and data collection regarding the environmental impacts generated during the production process at Company XYZ, therefore, this situation provide opportunities to find the hotspots of the process, the product comparison, potential impact to the environment as the impact of the battery container.

\subsection{Research objective}

To collect data and analyze the potential environmental impacts of the production process at Company XYZ (battery container type "X" and "Y") with the life cycle assessment approach using the IMPACT $2002+$ method.

\section{Methodology}

\subsection{Goal and scope definition}

The purpose of this study is to collect data and analyse the potential environmental impacts of the production process at PT XYZ (battery container type "X" and type "Y"). The scope used in the research is the gate to gate, which covers the production process from the injection process until the product is ready to be sent. The functional unit in this study is the production of battery container type "X" and type "Y" for 1 day at PT XYZ in July 2018. Data entered into the SimaPro software includes specific data (data collected by researchers) and built-in secondary data (data in the SimaPro 8.1.1.16 software database).

\subsection{Life cycle inventory}

Process production battery for both type of container through three similar processes as shown in Fig 1. The initial stage is an injection process that uses polypropylene material. The results of this stage are runners and battery containers. Runners are an avoided products that later be recycled. The battery container will be packaged using stretch film and transferred to the second process. The material used in the printing process is blue and pink colouring agent. The sequence starts from opening a stretch film that wraps the battery container. The stretch film then becomes waste. Battery container type X through 2 printing processes, but type $\mathrm{Y}$ have 1 additional printing processes. Next, the battery container will be arranged on a pallet, packed using stretch film, then they are sent to the ready warehouse. The third stage is the outgoing inspection, by picking-up and arranging a battery container from the warehouse, use a "TG" forklift. Before the final products are sent to the customer, the operator will check the battery container by opens the stretch film, repackaged, and then transferred to the truck, used by an "N" forklift. Waste in this process is a stretch film. 


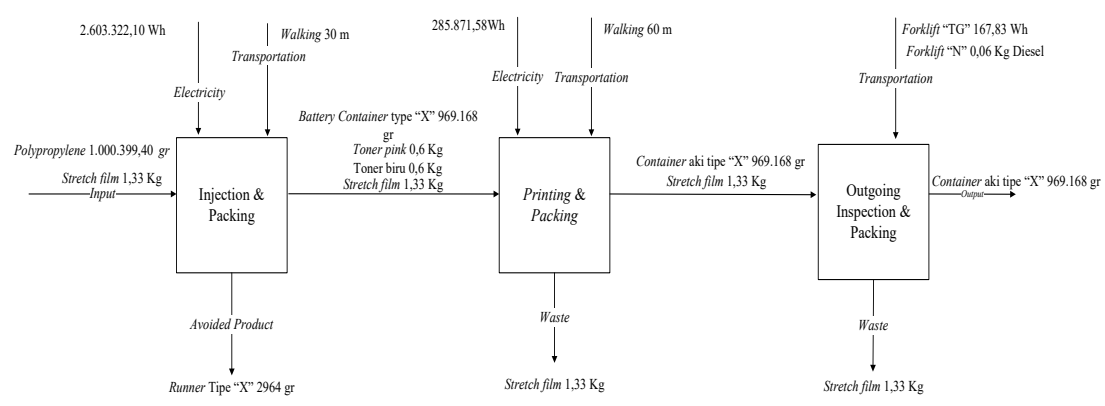

Fig. 1. Production process of battery container.

\subsection{Life cycle impact assessment}

This stage is the impact assessment stage, where researchers evaluate and analyse the output results from data processing using SimaPro 8.1.1.16 software with IMPACT 2002+ method. That method proposes a feasible implementation of a combined midpoint/ damage approach, linking all types of life cycle inventory results (elementary flows and other interventions) via 14 midpoint categories to four damage categories. For IMPACT 2002+ new concepts and methods have been developed, especially for the comparative assessment of human toxicity and eco-toxicity. Human Damage Factors are calculated for carcinogens and non-carcinogens, employing intake fractions, best estimates of dose-response slope factors, as well as severities. Other midpoint categories are adapted from existing characterizing methods (Eco-indicator 99 and CML 2002). All midpoint scores are expressed in units of a reference substance and related to the four damage categories human health, ecosystem quality, climate change, and resources [3]. Normalization can be performed either at the midpoint or at damage level. Output results that will be discussed are network diagram, damage assessment, and normalization.

\section{Result and discussion}

\subsection{Network diagram}

A network diagram is a depiction of the overall production process. From the network diagram it is known that from the whole process, the consumption of electrical energy in the battery container production process is the biggest contribution. This can be seen from the thickness of the red line. Electric energy consumption has the greatest contribution because all activities in the production process of battery containers use electrical energy starting from the machines in the injection process, printing process, crusher process, and refilling the "TG" forklift power. At the bottom, there is a green box, lignite meaning material. Lignite is brown coal which has the lowest quality among other types of coal. Lignite is used as a fuel to produce electricity. The total electrical energy used for the production process of the battery container type " $\mathrm{X}$ " is smaller than the production process type "Y" which is $\pm 2895.2 \mathrm{kWh}$ and $\pm 2969.6 \mathrm{kWh}$. The difference in the use of electrical energy from the battery type container " $\mathrm{X}$ " and type " $\mathrm{Y}$ " is the injection machine and the use of a longer printing machine. 
Fig. 2. Network diagram.

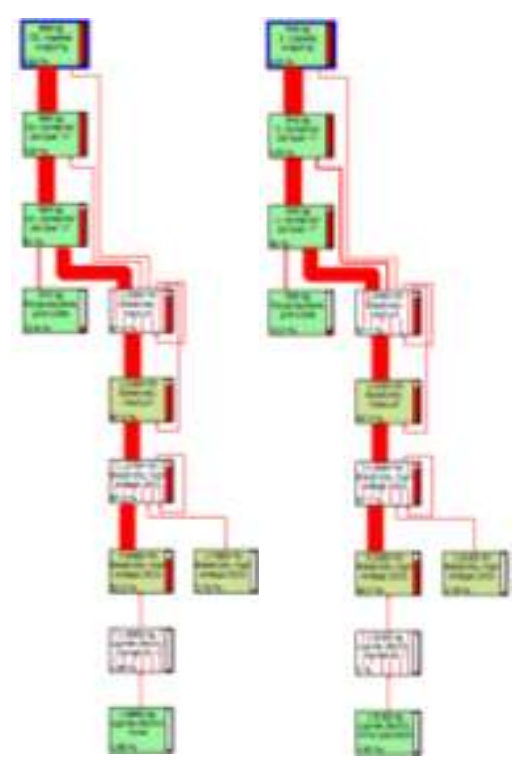

\subsection{Damage assessment}

Based on the IMPACT 2002+ method, the result of damage assessment shows that from four damage category, type " $\mathrm{X}$ " has a higher potential impact than type "Y" on category resources. And type " $Y$ " has a higher potential impact than type " $X$ " on category human health and ecosystem quality. The unit of the human health category is DALY (Disability Adjusted Life Year) which means the size received from the overall burden of the disease, expressed as the number of years lost due to disability, or premature death [4]. Pdf*m2*yr (potentially disappeared fraction of species over a certain area over a certain time) represents part of a species that has the potential to disappear in $1 \mathrm{~m}^{2}$ of the earth's surface for one year [4]. $\mathrm{Kg} \mathrm{CO}_{2}$ eq is used as a unit of the characterization category of the impact of global warming, and the effects are climate change globally [4]. MJ primary is the amount of basic energy needed to extract a natural resource [4].

\subsection{Normalization}

From Table I shows that the category of human health has the highest score, meaning that the production of battery type "X" and "Y" gives the greatest potential impact on the category of human health compared to the other three categories. 
Table 1. Damage category and normalization.

\begin{tabular}{|l|l|l|l|l|l|}
\hline & & \multicolumn{2}{|c|}{ Container } & \multicolumn{2}{c|}{ Normalization } \\
\hline Damage Category & Unit & Type X & Type Y & Type X & Type Y \\
\hline Human Health & DAYL & 0.0406 & 0.0412 & 5.72 & 5.8 \\
\hline Ecosystem Quality & PDF*m2*yr & 240 & 243 & 0.0175 & 0.0177 \\
\hline Climate Change & Kg CO2 eq & $4.81 \mathrm{E} 3$ & $4.82 \mathrm{E} 3$ & 0.486 & 0.486 \\
\hline Resources & MJ primary & $1.1 \mathrm{E} 5$ & $1.09 \mathrm{E} 5$ & 0.722 & 0.715 \\
\hline
\end{tabular}

The result of normalization per impact category is respiratory inorganics, non-renewable energy, and global warming. The three categories are caused by the use of electrical energy and PP raw materials. To reduce the potential for environmental impacts on the production process of battery containers type "X" and type "Y" at PT XYZ is by replacing the injection machine used to inject the battery container type "Y" with the machine that used for injection type " $\mathrm{X}$ " because of the smaller power usage. If the injection machine is replaced, it can reduce electricity usage by $38.400 \mathrm{Wh}$ (equivalent to $28.6 \mathrm{Kg} \mathrm{CO}_{2}$ eq). The value of $28.6 \mathrm{Kg} \mathrm{CO}_{2}$ eq is equivalent to $\mathrm{CO}_{2}$ emissions from burning 31.3 pounds $(14.2 \mathrm{~kg}$ ) of coal, or $\mathrm{CO}_{2}$ emissions from gasoline consumption of 3.2 gallons (12.11 litres) [5].

The following is an example of a comparison of carbon emissions generated from an injection machine that is used to produce battery containers type " $\mathrm{X}$ ", battery containers type "Y" and plant $Z$. Data from the plant $Z$ injection machine is obtained from Saputra and Hanafi (2017) [6]. Comparisons were made using plant $X$ injection machine data because there were similarities, the machine in plant $\mathrm{Z}$ was a moulding injection machine and used polypropylene input material. For the use of polypropylene, the "X" injection machine processes $333.47 \mathrm{Kg} / 8$ hours, the injection machine "Y" type $329.27 \mathrm{Kg} / 8$ hours, and the injection machine plant $X$ processes $400 \mathrm{Kg} / 8$ hours. The results of data processing are carbon emissions generated from injection machines of type $\mathrm{X}, \mathrm{Y}$ and Plant $\mathrm{Z}$ are 4.62, 4.7 and $2.59 \mathrm{Kg} \mathrm{CO}$ eq. The calculation shows that the difference in carbon emissions produced between injection machines type $\mathrm{X}$ and injection machines plant $\mathrm{Z}$ is $2.03 \mathrm{Kg}$ $\mathrm{CO}_{2}$ eq, which mean they are not significantly differed. While the difference in carbon emissions between injection machines type $\mathrm{Y}$ and injection machines plant $\mathrm{Z}$ is $2.11 \mathrm{Kg}$ $\mathrm{CO}_{2}$ eq.

\section{Conclusions}

1. Results of with the IMPACT $2002+$ method shows that the potential environmental impact is more dominant in these categories: respiratory inorganics, non-renewable energy, and global warming. These three categories are the highest category of environmental impact among the 15 impact categories midpoint.

2. The component which caused the greatest potential for respiratory inorganics and global warming is coming from electrical energy consumption (lignite). Meanwhile, the component which possessed the greatest impact on non-renewable energy comes from polypropylene (PP) material.

3. The battery container type "X" and "Y" has a potential impact of 0,0406 and 0,0412 DALY in the human health category, 240 and $243 \mathrm{PDF}^{*} \mathrm{~m} 2 * \mathrm{yr}$ in the ecosystem quality category, $4,81 \mathrm{E} 3$ and $4,82 \mathrm{E} 3 \mathrm{Kg} \mathrm{CO}_{2}$ eq in the category of climate change, and $1,1 \mathrm{E} 5$ and 1,09E5 MJ Primary in the resources category.

4. The company has a lot of work to do to achieve sustainable production and consumption. However, the first step in life cycle assessment is a big leap for the company. The next possible thing to do is the plan to make a sustainability report. 


\section{References}

1. Kemenperin: Pelaku Industri Banyak Menghadapi Tantangan. http://kemenperin.go.id/artikel/6302/Pelaku-Industri-Banyak-Menghadapi-Tantangan. (2013)

2. M.Z. Hauschild, R.K.R.S.I Olsen, Life Cycle Assessment Theory and Practice (Springer, 2018)

3. O. Jolliet, M. Margni, R. Charles, S. Humbert, J. Payet, G. Rebitzer, R. Rosenbaum, Indonesian Journal Life Cycle Assessment 6 (2003)

4. S. Humbert, An De Schryver, M. Margni, O. Jolliet. IMPACT 2002+: User Guide Draft for Version Q2.2 (Version Adapted by Quantis) (2012)

5. US EPA, OAR, OAP, CPPD. n.d. "Greenhouse Gas Equivalencies Calculator." Accessed July 30, 2018. https://www.epa.gov/energy/greenhouse-gas-equivalenciescalculator.

6. S.Y. Saputra, J. Hanafi, Indonesian Journal of Life Cycle Assessment and Sustainability (2017)

7. Simapro Software www.simapro.com

8. Inventory of U.S. Greenhouse Gas Emissions and Sinks: 1990-2015

9. Highway Statistics 2015 (Office of Highway Policy Information, Federal Highway Administration, 2015)

10. ISO, Environmental Management-Life Cycle Assessment-Requirements and Guidelines (ISO 14044) (ISO, Geneva, 2006) 